\title{
Experimental host preference of diapause and non-diapause induced Culex pipiens pipiens (Diptera: Culicidae)
}

\author{
Ary Faraji ${ }^{1,2^{*}}$ and Randy Gaugler ${ }^{1}$
}

\begin{abstract}
Background: Culex pipiens pipiens plays an important role in the transmission of several vector-borne pathogens such as West Nile virus (WNV) in North America. Laboratory and field studies suggest that this species is ornithophilic but because of genetic hybridization with sibling species during the active mosquito season, it may occasionally feed on mammals. Adult female $C x$. p. pipiens undergo a facultative diapause and may serve as an overwintering mechanism for WNV. To determine the effect of diapause on the innate host preference of $C x$. p. pipiens emerging from winter hibernation, we conducted host-choice experiments using bird and mammal hosts.

Methods: Mosquitoes were reared under non-diapause induced (NDI), diapause induced (DI), and field collected from overwintering (OW) hibernaculae. They were released into a large mesh enclosure housing two lard can traps, and given a choice between feeding on a dove or a rat.

Results: Host seeking Cx. p. pipiens were four times more likely to feed on the dove than the rat, regardless of experimental conditions. Under NDI conditions, $C x$. p. pipiens were $(p<0.001)$ more attracted to the bird (79.9 \% [75.6-84.1]) than the rat (20.1 [15.9-24.4]). Overwintering mosquitoes and those exposed to DI conditions were also significantly $(p<0.001)$ more attracted to birds $(81.6 \%[75.9-87.3])$ than to rats $(18.5[12.7-24.2])$.

Conclusions: We provide new information about the innate host preference of $C x$. p. pipiens emerging from diapause in temperate habitats where winter survival is crucial for disease transmission cycles. Although we showed that CX.p. pipiens prefers an avian to a mammalian host, nearly $20 \%$ of emerging mosquitoes in the spring could feed on mammals. Changes in host preferences may also contain valuable clues about transmission dynamics and subsequent timely interventions by vector control and public health practitioners.
\end{abstract}

Keywords: Host selection, Avian feeding, Mammalian feeding, Overwintering, Bird-baited traps

\section{Background}

West Nile virus (WNV) and St. Louis encephalitis (SLE) are serious public and veterinary health concerns. These viruses are primarily maintained in an enzootic cycle involving ornithophilic Culex mosquitoes and avian amplification hosts [1-3]. Although mammals succumb to arboviral infections, they do not develop prolonged or high levels of viremia and are considered dead-end or dilution hosts [4]. Increased mammalian feeding by the primary vectors will negatively affect disease ecology

\footnotetext{
*Correspondence: ary@slcmad.org

'Center for Vector Biology, Department of Entomology, Rutgers University, New Brunswick, New Jersey 08901-8536, USA

${ }^{2}$ Salt Lake City Mosquito Abatement District, 2020 North Redwood Road, Salt Lake City, Utah 84116-1248, USA
}

because amplification of these avian zoonoses depend on virus consistently reaching competent hosts.

Culex pipiens pipiens $\mathrm{L}$. has been incriminated as the primary enzootic vector of WNV and SLE throughout its geographic range $[1,2,5,6]$. This mosquito belongs to a complex of evolutionarily and morphologically closely related species which differ dramatically in biology, ecology, and vectorial capacity $[2,7]$. In northeastern USA, $C x . p$. pipiens populations are composed of two forms: $C x . p$. pipiens form "pipiens" and Cx. p. pipiens form "molestus" $[2,8]$. Culex $p$. pipiens form pipiens develops in above ground larval habitats, mates in swarms within open areas, undergoes a facultative winter diapause, requires a blood meal to develop eggs, and primarily feeds on birds $[2,7,9]$. 
Conversely, $C x$. $p$. pipiens form molestus develops in underground larval habitats, mates in confined spaces, remains active throughout winter in sequestered subterranean habitats, can produce the first batch of eggs autogenously, and prefers to feed on mammals [2, 9]. The pipiens and molestus forms are generally reproductively isolated in nature, but occasionally hybridize, producing females that may feed indiscriminately on avian or mammalian hosts $[6,8-13]$. Thus, the primary enzootic vector may also serve as an epizootic or epidemic bridge vector in ecological cycles of mosquito-borne pathogens in northeastern USA [6, 12].

Field investigations in northeastern USA have shown that Cx. p. pipiens derive $93-96 \%$ of their blood meals from avian sources [14-17]. However, additional field evidence from the mid-Atlantic and upper Midwestern USA have shown that some populations may derive $13-22 \%$ of their blood meals from mammalian sources [12, 18]. However, higher fractions of molestus ancestry have been detected in Cx. p. pipiens populations with mammalian-derived blood meals [10, 13]. It has been hypothesized that genetic ancestry may drive $C x . p$. pipiens to occasionally feed on mammals, but the rates of vector-host contact may also be influenced by other factors. These include the innate host preference of the vector, host availability, spatial or temporal variations, and even the method of sampling for host feeding determinations [19]. But an overlooked factor is the effect of diapause on the host preference of emerging populations of $C x$. p. pipiens.

Diapause is the primary mechanism for survival in temperate environments. Diapause is a genetically determined response by which an insect enters a dormant state in response to environmental cues which indicate the onset of unfavourable conditions [20]. The dynamic state of winter diapause in $C x$. p. pipiens is induced primarily by decreasing photoperiodic signals in the late summer and fall, and is often enhanced by cooling temperatures [7, 21-23]. Females emerging from pupae under these conditions do not blood feed but instead sequester fat bodies from carbohydrate sources, mate with males and store spermatozoa in spermatheca, seek shelter inside a hibernacula, and enter into a state of reproductive (ovarian) diapause [24-27]. The ovarian follicles of diapausing $C x . p$. pipiens are in a state of arrest that are easily distinguishable from their summer resting stage through follicular morphometric examinations $([22,25]$. A small number of females may also become infected with arboviruses, such as WNV, through vertical (or transgenerational) transmission and may serve as a winter reservoir for the virus [28-34].

For WNV and SLE, diapausing Cx. p. pipiens mosquitoes are critical for harboring the viruses during winter and subsequently reintroducing them as disease agents the following spring [25, 28, 29, 35]. Diapause also regulates the size and synchronization of mosquito populations the following season. In northeastern USA, $C x . p$. pipiens mosquitoes emerge from hibernation in April-May [22, 25, 36] and are considered critical for initiating WNV transmission among birds in the early spring $[1,37]$. However, although extrinsic factors such as temperature and rainfall affect the intensity of WNV transmission [3], it is unclear why WNV levels remain consistently low until mid-summer, even after suitable temperatures for viral replication have been reached $[38,39]$. We hypothesize that a reason for the weakened early season amplification of WNV may be that $C x . p$. pipiens emerging from diapause may be feeding more frequently on mammals, which are incompetent hosts, versus the more competent avian amplification hosts. This may dampen the intensity of WNV transmission in most host communities in the early season and may explain the reduced levels of WNV detected in the spring.

We examined the attractiveness of non-diapause (NDI) and diapause induced (DI) Cx. p. pipiens mosquitoes to a dove or a rat via a series of host-choice experiments. We established colonies of $C x$. p. pipiens collected as egg rafts and exposed them to simulated NDI or DI conditions and then determined the host selection of adults under laboratory conditions. We also collected overwintering (OW) $C x . p$. pipiens from field hibernaculae, terminated ovarian diapause, and exposed the mosquitoes to the same hostchoice experiments. Our primary question was to determine if $C x . p$. pipiens emerging from winter diapause will feed indiscriminately on avian or mammalian hosts.

\section{Methods \\ Mosquitoes}

Culex $p$. pipiens mosquitoes used in our host selection trials were reared from field-collected egg rafts in Trenton, New Jersey, USA (40 $\left.14^{\circ} 23.62^{\prime \prime} \mathrm{N}, 74^{\circ} 44^{\prime} 26.98^{\prime \prime} \mathrm{W}\right)$. Local egg raft collections and laboratory rearing would ensure that adequate numbers of mosquitoes of the same physiological status and age were available for all experiments. We used black gravid trap pans $(20 \mathrm{x} 38 \times 12.7 \mathrm{~cm}$, BioQuip, Rancho Dominguez, CA, USA) filled with a fermented mixture of grass clippings and de-chlorinated tap water [40]. Egg rafts were collected in the morning and transported to the laboratory. Individual egg rafts were allowed to hatch in separate larval rearing trays containing $2 \mathrm{~L}$ of de-chlorinated tap water. Larvae from the same egg batch were reared in separate $20 \mathrm{~cm} \times 30 \mathrm{~cm}$ stainless steel pans, fed finely ground rat chow on alternate days, and trays were skimmed daily to remove exuviae and debris following standard protocols [41]. All larvae were reared in incubators to ensure consistent temperature, humidity, and photoperiod regimes. Species identification was conducted on fourth instars and confirmed on adult specimens using standard keys [42].

Non-diapause induced larvae were reared under $27^{\circ} \mathrm{C}$, $70 \% \mathrm{RH}$, and 16:8 h (L:D) photoperiod. Emerging adults were transferred to screened cages $(30.5 \times 30.5 \times 30.5 \mathrm{~cm}$, 
BioQuip, Rancho Dominguez, CA, USA), provided a $10 \%$ sucrose solution, and maintained under the same conditions as above. Female $C x$. p. pipiens used in the host selection trials were five days post-emergence and deprived of sucrose solution $12 \mathrm{~h}$ prior to testing. Five females were retained from each replicate for ovarian dissections to record follicular morphometrics of ovarioles and confirm physiological status.

Diapause induced larvae were reared under $10{ }^{\circ} \mathrm{C}, 70 \%$ $\mathrm{RH}$, and a photoperiod of 8:16 h to ensure induction of diapause $[22,25,43]$. Emerging adults were transferred to screened cages, provided a $10 \%$ sucrose solution, and maintained under the same conditions as above for four weeks. Five female $C x$. p. pipiens were retained from each batch for dissections to confirm ovarian diapause induction. Diapause was then terminated by exposing the mosquitoes to NDI conditions $\left(27{ }^{\circ} \mathrm{C}, 70 \% \mathrm{RH}, 16: 8 \mathrm{~h}\right.$ photophase) for one week. Five additional adult females were again retained for dissections to confirm diapause termination. Subsequent adult female $C x$. $p$. pipiens were then deprived of sucrose solution for $12 \mathrm{~h}$ prior to each host selection trial.

Field collections of overwintering Cx. p. pipiens were conducted within the abandoned underground ammunition bunkers of Fort Mott, Pennsville, New Jersey, USA $\left(39^{\circ} 36^{\prime} 14.85^{\prime \prime} \mathrm{N}, 75^{\circ} 33^{\prime} 13.47^{\prime \prime} \mathrm{W}\right)$. Mosquitoes were collected on six different occasions between November 2010 to March 2011. Female mosquitoes were gently aspirated and placed in coolers with ice packs for transport back to the laboratory. Five females were retained from each collection for dissections to confirm ovarian diapause status. In the laboratory, mosquitoes were placed in screened cages, provided a $10 \%$ sucrose solution, and exposed to NDI conditions $\left(27^{\circ} \mathrm{C}, 70 \% \mathrm{RH}, 16: 8 \mathrm{~h}\right.$ photophase) for one week to terminate diapause. Five adult females were retained for dissections to confirm diapause termination. Subsequent $C x . p$. pipiens females were then deprived of the sucrose solution for $12 \mathrm{~h}$ prior to each host selection trial.

\section{Dissection methods}

Dissections were conducted under a stereomicroscope with dissecting needles using the ovariolar separation technique of Hoc and Schaub [44]. Ovaries were teased apart to expose individual follicles for examination and measurement under $400 \mathrm{X}$ phase contrast microscopy [28]. Five ovarioles from each female were randomly selected and the developmental stage of the primary follicle was recorded using Christophers and Mer stages [45]. In addition, the length of the primary and secondary follicles was measured for five ovarioles of each female using an ocular micrometer, and a mean value was recorded. Measurements were used to calculate the ratio of the primary to secondary follicle for determination of ovarian diapause induction [24]. Ovarian diapause in $C x$. p. pipiens is characterized by primary follicles which measure $\leq 50 \mu \mathrm{m}$ ( $\geq 70 \mu \mathrm{m}$ in NDI mosquitoes) and exhibit a primary to secondary follicular ratio of $\leq 1.6$ ( $\geq 2.0$ in NDI mosquitoes) $[24,25]$.

\section{Animals and cages}

We tested white rock dove birds, Columbia livia Gmelin, and white rats, Rattus norvegicus (Berkenhout), of similar body mass (ca. $300 \mathrm{~g}$ ) for all host selection trials. Animals were weighed prior to each trial and rotated with each subsequent experiment so that the same animal was not used for consecutive trials. We followed guidelines set forth in the Guide for the Care and Use of Laboratory Animals [46] as approved by the Animal Use Committee of Rutgers University under protocol No. 86-129.

A single animal was placed inside a cylindrical lard can trap $(25 \times 25 \times 70 \mathrm{~cm})$ [47-49] with 2-cm mesh screening to confine the animal but allow for host odour emanation (Fig. 1). Mosquitoes entered the trap through one of two removable funnels on either end of the trap. The funnels contained a mosquito-proof mesh that prevented direct contact between the animals and mosquitoes. Lard can traps were placed inside a larger mesh enclosure $(3 \times 3 \times 3 \mathrm{~m})$ within the laboratory (Fig. 1). Entry to the enclosure for placement of the lard can traps was gained by a $1.5 \times 2.5 \mathrm{~m}$ door and an additional $25 \times 25 \mathrm{~cm}$ window lined with stretchable cotton cloth sleeve material allowed for insertion of mosquitoes during trials. The enclosure was lined with mosquito-proof mesh and further covered with clear vinyl plastic to retain humidity.

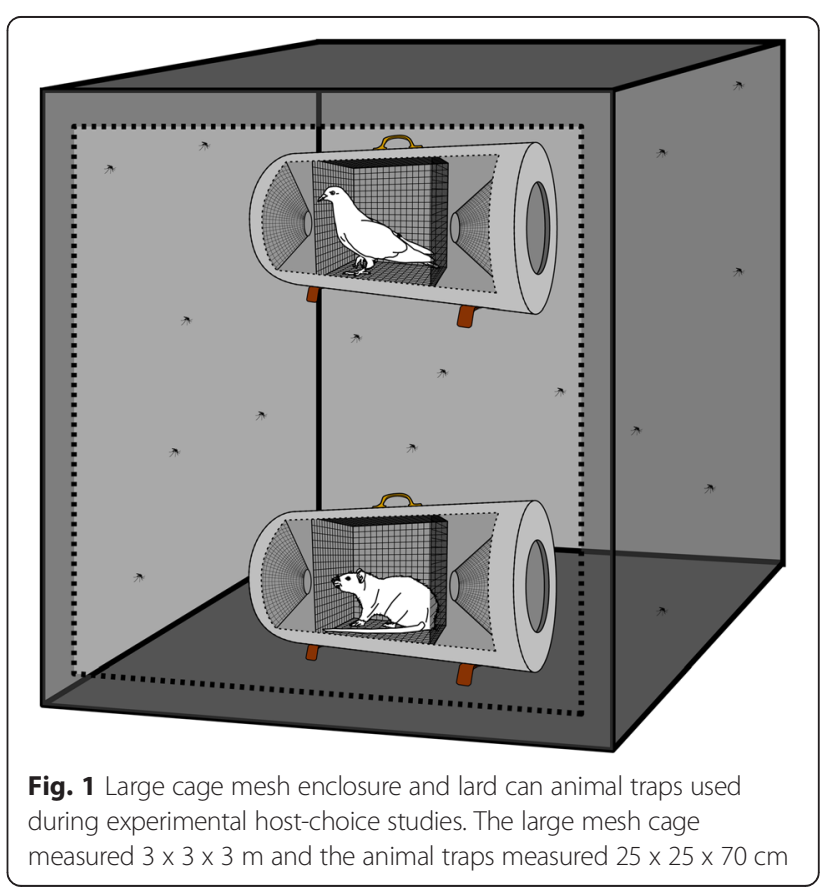




\section{Host-choice experiments}

We conducted three primary host-choice experiments using NDI, DI, and overwintering mosquitoes. We released 25-70 Cx. p. pipiens females from the same egg batch or collection for each trial, depending on the number of available specimens. Each experiment was repeated four times to allow for placement of the bird or rat in the up and down positions. Experiments consisted of a total of 48 replicates using 1,589 mosquitoes (NDI), 36 replicates with 701 mosquitoes (DI), and 40 replicates with 2,285 mosquitoes (overwintering). Each trial was conducted $1 \mathrm{~h}$ before sunset to $1 \mathrm{~h}$ post sunrise under $27{ }^{\circ} \mathrm{C}, 70 \% \mathrm{RH}$, and 16:8 h photophase. During each experiment, a rock dove was placed in a lard can trap hung from a small hook from the inside ceiling of the mesh enclosure (Bird Up position) and a rat was placed in another lard can trap and positioned on the floor of the mesh enclosure (Rat Down). The two animals were separated by $2.5 \mathrm{~m}$. The position of the animals was rotated the following night (Rat Up, Bird Down) and the experiment repeated on consecutive nights. The host animals and position were rotated with each subsequent trial. Mosquitoes entering lard can traps were removed and placed on dry ice for sorting and counting while those remaining in the mesh enclosure were removed by aspiration.

\section{Data analysis}

Confidence intervals surrounding the estimated proportion of $C x$. p. pipiens selecting a particular host were calculated using the formula $95 \% \mathrm{CI}= \pm 1.96 \times$ (square root $p(1-p) / \mathrm{n})$, where $p=$ the proportion of $C x . p$. pipiens attracted to a given animal source, and $n=$ the total number of $C x . p$. pipiens responding (entering the lard can traps) [50]. Before statistical analysis, data were tested with Levene's test for homogeneity of variance and $\log (x+1)$ transformed. An analysis of variance
(ANOVA) was used to determine if host groups or position (up or down) was significant between and within each trial (NDI, DI, OW). After we found a nonsignificant interaction for group or position, data for each host type were combined to test for differences in the proportion of $C x . p$. pipiens attracted to the bird or rat by using Pearsons $\chi^{2}$ analysis for trend. All analyses were performed using IBM SPSS Statistics 21 (IBM, Armonk, NY, USA).

\section{Results}

\section{Mosquitoes and ovarian dissections}

Non-diapause induced mosquitoes contained primary follicles of $90.13 \mu \mathrm{m}( \pm 0.76 \mathrm{SE})$, secondary follicles of $31.49 \mu \mathrm{m}( \pm 0.27)$, and a primary/secondary ratio of 2.90 $( \pm 0.03)$ (Fig. 2). Diapause induced mosquitoes contained primary follicles of $52.38 \mu \mathrm{m}( \pm 0.31)$, secondary follicles of $38.45 \mu \mathrm{m}( \pm 0.27)$, and a ratio of $1.37( \pm 0.01)$ (Fig. 2). When diapause was terminated in the DI group, their ovarioles had resumed development with primary follicles of $86.98 \mu \mathrm{m}( \pm 0.94)$, secondary follicles of $31.75 \mu \mathrm{m}( \pm 0.36)$, and a ratio of $2.76( \pm 0.03)$. Field collected OW mosquitoes possessed ovarioles measuring $51.94 \mu \mathrm{m}( \pm 0.28)$ for primary follicles, $38.79 \mu \mathrm{m}( \pm 0.23)$ for secondary follicles, and a ratio of $1.34( \pm 0.01)$. Terminating diapause in these mosquitoes resumed development of ovarioles and measured $91.20 \mu \mathrm{m}( \pm 0.97)$ for primary follicles, $34.05 \mu \mathrm{m}( \pm 0.37)$ for secondary follicles, and a ratio of $2.69( \pm 0.02)$.

\section{Host-choice experiments}

Host seeking $C x . p$. pipiens were four times more likely to feed on rock doves than rats, regardless of experimental conditions (Table 1). The distribution for the host-choice experiments is represented by the box plots in Fig. 3. Nearly $82 \%(\mathrm{n}=694)$ of $C x$. p. pipiens preferred the bird versus $18 \%(\mathrm{n}=158)$ for the rat. Under NDI conditions, $C x . p$. pipiens were significantly $(\chi 2=377.0 ; \mathrm{df}=1 ; p<0.001)$

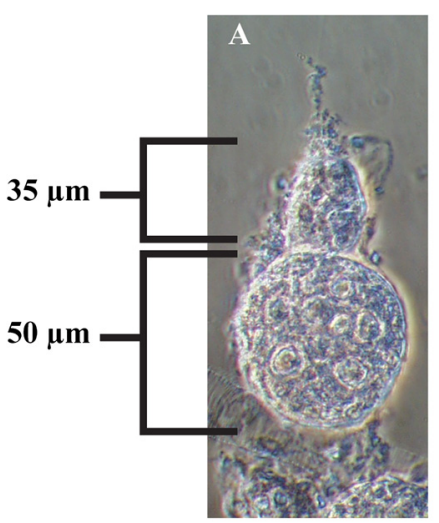

Ratio $=\mathbf{1 . 4 3}$

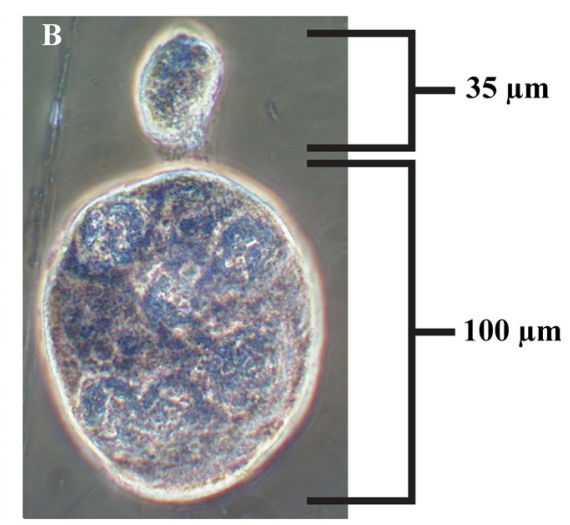

Ratio $=\mathbf{2 . 8 6}$

Fig. 2 Representative ovarioles from an unengorged Culex pipiens pipiens. a ovariole from a diapausing mosquito; b ovariole from a non-diapause induced mosquito. Ratio values represent the difference in size between the primary and secondary follicles 
Table 1 Host-choice experiment results of Culex pipiens pipiens under non-diapause induced (NDI), diapause induced (DI), and field overwintering (OW) conditions

\begin{tabular}{|c|c|c|c|c|c|c|c|}
\hline Condition & Host & No. trials & No. released & $\begin{array}{l}\text { No. in all traps } \\
(\% \text { [95 \% Cl]) }\end{array}$ & $\begin{array}{l}\text { No. in bird trap } \\
(\%[95 \% \text { CI]) }\end{array}$ & $\begin{array}{l}\text { No. in rat trap } \\
(\% \text { [95 \% CI]) }\end{array}$ & $x^{2}$ \\
\hline \multirow[t]{3}{*}{ NDI } & Bird up - Rat down & 24 & 959 & $292(30.5[27.5-33.4])$ & 236 (80.8 [76.3-85.3]) & 56 (19.2 [14.7-23.7]) & \\
\hline & Bird down - Rat up & 24 & 630 & $51(8.1[6.0-10.2])$ & $38(74.5$ [62.6-86.5]) & $13(25.5[13.5-37.5])$ & \\
\hline & Total Bird - Rat & 48 & 1,589 & 343 (21.6 [19.6-23.6]) & 274 (79.9 [75.6-84.1]) & 69 (20.1 [15.9-24.4]) & $p<0.001$ \\
\hline \multirow[t]{3}{*}{ DI } & Bird up - Rat down & 18 & 349 & 79 (22.6 [18.3-27.0]) & 61 (77.2 [68.0-86.5]) & $18(22.8[13.5-32.0])$ & \\
\hline & Bird down - Rat up & 18 & 352 & $21(6.0[3.5-8.4])$ & 19 (90.5 [77.9-99.0]) & $2(9.5[0.1-22.1])$ & \\
\hline & Total Bird - Rat & 36 & 701 & 100 (14.3 [11.7-16.9]) & 80 (80.0 [72.2-87.8]) & $20(20.0$ [12.2-27.8]) & $p<0.001$ \\
\hline \multirow[t]{3}{*}{ OW } & Bird up - Rat down & 20 & 1,331 & 227 (17.1 [15.0-19.1]) & 169 (74.5 [68.8-80.1]) & 58 (25.6 [19.9-31.2]) & \\
\hline & Bird down - Rat up & 20 & 954 & $182(19.1$ [16.6-21.6]) & 171 (94.0 [90.5-97.4]) & $11(6.0$ [2.6-9.5]) & \\
\hline & Total Bird - Rat & 40 & 2,285 & 409 (17.9 [16.3-19.5]) & 340 (83.1 [79.5-86.8]) & 69 (16.9 [13.2-20.5]) & $p<0.001$ \\
\hline
\end{tabular}

more attracted to the bird (79.9\% [75.6-84.1]) than the rat (20.1 [15.9-24.4]) (Table 1). Culex p. pipiens exposed to DI conditions were also significantly $(\chi 2=100.0 ; \mathrm{df}=1 ; p$ $<0.001)$ more attracted to birds (80.0\% [72.2-87.8]) than to rats $(20.0$ [12.2-27.8]) (Table 1). Overwintering mosquitoes collected from the field and subjected to our host-choice experiments also showed a significant $(\chi 2=341.0 ; \mathrm{df}=1 ; p<0.001)$ attraction to birds $(83.1 \%$ [79.5-86.8]) than to rats (16.9 [13.2-20.5]) (Table 1).

\section{Discussion}

Our study shows that when offered a choice, $C x . p$. pipiens strongly prefers an avian over a mammalian host. Previous laboratory and field studies have also shown distinct ornithophagic patterns for $C x . p$. pipiens and have even documented behavioral preferences for certain species of birds [14-17, 49, 51]. However, in our experiments the degree of preference did not vary based on physiological status of the mosquitoes (NDI or DI). This indicates that overwintering mosquitoes emerging from hibernaculae in the spring prefer to feed on available wild birds rather than mammals. However, our design provides a measure of preference under laboratory conditions for only a single avian and mammalian species, and does not take into consideration the attractiveness of other hosts from the same class. For example, the host attractiveness of different birds to mosquitoes may vary for each individual species $[19,49]$. Additionally, it is also crucial to consider other important variables such as habitat type, vector abundance, genetic ancestry, host density, and host brooding or defensive behavior [17, 52-58].

Previous host feeding studies conducted in the northeastern USA have shown that Cx. p. pipiens derives $>90 \%$ of their blood meals from birds [14-17], while some studies have reported up to $38 \%$ mammalian feedings $[10,12,50]$.

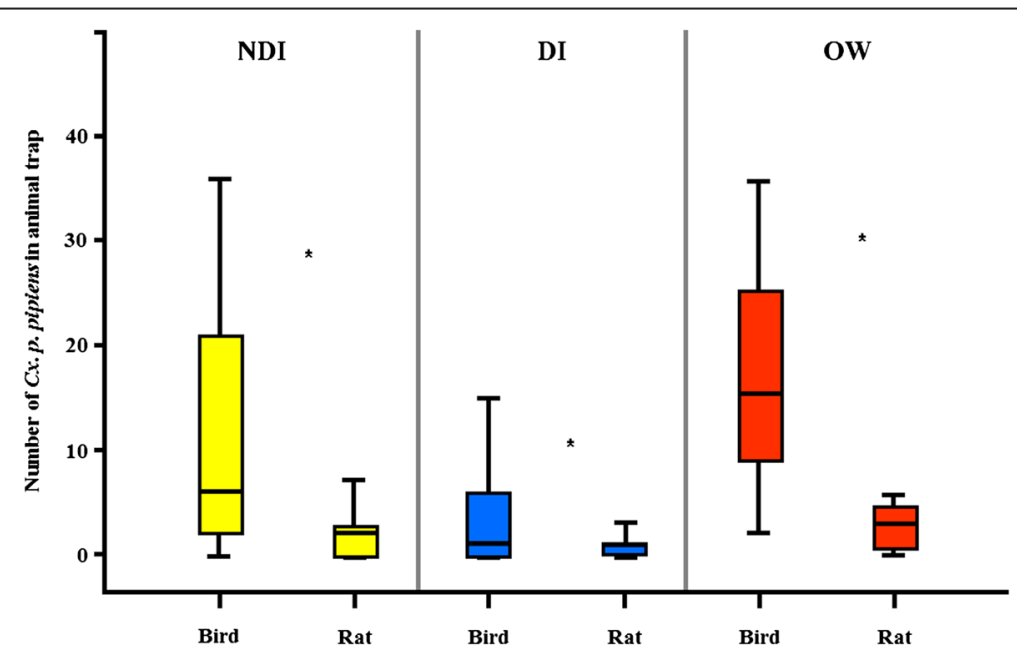

Fig. 3 Box plot representing host-choice feeding rates of Culex pipiens pipiens under non-diapause induced (NDI), diapause induced (DI), and field overwintering (OW) conditions. Median values are represented by horizontal bar within the boxes and whiskers represent 1.5 SE. Asterisks indicate significant differences between animal hosts (Chi-square tests, $P<0.001$ ) 
However, mammalian feeding in $C x$. $p$. pipiens has been attributed to genetic introgressive hybridization from $C x$. p. pipiens form molestus populations [10, 12, 18]. But these earlier studies were conducted solely during the mid-summer when $C x . p$. pipiens populations are abundant, and not during the early season when mosquitoes are emerging from winter diapause. Since molestus populations are incapable of diapause [22, 25], it is improbable that introgression would be occurring in the early season populations. Similar to our experimental overwintering studies, it is expected that overwintering populations undergoing a facultative ovarian diapause are pure populations of Cx. p. pipiens. Irrespective, DI and OW mosquitoes in our host-choice experiments which had terminated diapause (to simulate emergence from hibernation in the spring) displayed nearly a $20 \%$ affinity for a mammalian host.

A dilution effect hypothesis has been shown for WNV and nonpasserine diversity before $[18,59,60]$, but not during the early season, when the primary enzootic vectors are reinitiating introduction of virus back into host communities. If the primary enzootic amplification vectors feed more indiscriminately on non-competent mammalian hosts, particularly during the most vulnerable period following spring emergence, then this would reduce contact rates away from important avian amplifying hosts and may dampen the intensity of transmission in most host communities. However, during our studies we observed a significant preference for avian hosts by $C x . p$. pipiens, regardless of the environmental conditions. We again reiterate that our studies were conducted in simulated laboratory conditions and may not reflect the influence of other variables as mentioned above. Further field studies should investigate the host preference of $C x . p$. pipiens emerging from diapause and evaluate ecological and biological factors that may influence host selection and thus disease dynamics.

\section{Conclusions}

Our findings provide additional information about the innate host preference of $C x . p$. pipiens emerging from winter diapause in temperate habitats where bridging unfavourable seasons is crucial for disease transmission cycles. For pathogens that utilize the primary vector as a winter reservoir, diapause success not only affects vector population densities, but may also have substantial epidemiological significance. Changes in host preference choices may also contain valuable clues about transmission dynamics and subsequent timely interventions by vector control and public health practitioners. It is also unclear what the impact of global climate change and its effect on diapause dynamics will have on vector populations and pathogen transmission. Future studies, using ecologically relevant temporal, spatial, host, and vector species are required to better assess the role of these variables in disease cycles.

\section{Abbreviations \\ Cx. p. pipiens: Culex pipiens pipiens; DI: Diapause induced; L: Linnaeus; NDI: Non-diapause induced; OW: Overwintering; SLE: St. Louis encephalitis virus; WNV: West Nile virus.}

\section{Competing interests}

The authors declare that they have no competing interests.

\section{Authors' contributions}

AF and RG conceived and designed the experiments. AF carried out the experiments and analysed the data. AF and RG drafted the manuscript. All authors read and approved the final manuscript.

\section{Acknowledgments}

We are in sincere gratitude to Isik Unlu, without whose friendship, assistance, and input these experiments would not have been possible. We thank Dina Fonseca for encouraging us to carry out the experiments and for help in experimental design, James Pulaski for digital creation and manipulation of the figures, and Chris Borow, Nick Indelicato, Mike Milewski, and Ron

Oppenheimer for technical assistance.

Received: 22 June 2014 Accepted: 20 July 2015

Published online: 24 July 2015

\section{References}

1. Andreadis TG, Anderson JF, Vossbrinck CR, Main AJ. Epidemiology of West Nile virus in Connecticut: a five-year analysis of mosquito data 1999-2003. Vector Borne Zoonotic Dis. 2004;4:360-78.

2. Farajollahi A, Fonseca DM, Kramer LD, Kilpatrick AM. "Bird biting" mosquitoes and human disease: a review of the role of Culex pipiens complex mosquitoes in epidemiology. Infect Genet Evol. 2011;11:1577-85.

3. Kramer LD, Styer LM, Ebel GD. A Global Perspective on the Epidemiology of West Nile Virus. Annu Rev Entomol. 2008:53:61-81.

4. Swaddle JP, Calos SE. Increased avian diversity is associated with lower incidence of human West Nile infection: observation of the dilution effect. PLoS One. 2008;3:e2488.

5. Turell MJ, Dohm DJ, Sardelis MR, O'guinn ML, Andreadis TG, Blow JA. An update on the potential of North American mosquitoes (Diptera: Culicidae) to transmit West Nile virus. J Med Entomol. 2005;42:57-62.

6. Kilpatrick AM, Kramer LD, Campbell SR, Alleyne EO, Dobson AP, Daszak P. West Nile virus risk assessment and the bridge vector paradigm. Emerg Infect Dis. 2005;11:425-9.

7. Vinogradova EB. Culex pipiens pipiens mosquitoes: taxonomy, distribution, ecology, physiology, genetic, applied importance and control. Sofia, Bulgaria: Pensoft Publishers; 2000.

8. Huang S, Molaei G, Andreadis TG. Genetic insights into the population structure of Culex pipiens (Diptera: Culicidae) in the northeastern United States by using microsatellite analysis. Am J Trop Med Hyg. 2008;79:518-27.

9. Fonseca DM, Keyghobadi N, Malcolm CA, Mehmet C, Schaffner F, Mogi M, et al. Emerging vectors in the Culex pipiens complex. Sci. 2004;303:1535-8.

10. Huang S, Hamer GL, Molaei G, Walker ED, Goldberg TL, Kitron UD, et al. Genetic variation associated with mammalian feeding in Culex pipiens from a West Nile virus epidemic region in Chicago, Illinois. Vector Borne Zoonotic Dis. 2009;9:637-42.

11. Hamer GL, Kitron UD, Goldberg TL, Brawn JD, Loss SR, Ruiz MO, et al. Host selection by Culex pipiens mosquitoes and West Nile virus amplification. Am J Trop Med Hyg. 2009;80:268-78.

12. Hamer GL, Kitron UD, Brawn JD, Loss SR, Ruiz MO, Goldberg TL, et al. Culex pipiens (Diptera: Culicidae): a bridge vector of West Nile virus to humans. J Med Entomol. 2008;45:125-8.

13. Kilpatrick AM, Kramer LD, Jones MJ, Marra PP, Daszak P, Fonseca DM. Genetic influences on mosquito feeding behavior and the emergence of zoonotic pathogens. Am J Trop Med Hyg. 2007;77:667-71.

14. Apperson CS, Harrison BA, Unnasch TR, Hassan HK, Irby WS, Savage HM, et al. Host-feeding habits of Culex and other mosquitoes (Diptera: Culicidae) in the Borough of Queens in New York City, with characters and techniques for identification of Culex mosquitoes. J Med Entomol. 2002;39:777-85. 
15. Molaei G, Andreadis TG, Armstrong PM, Anderson JF, Vossbrinck CR. Host feeding patterns of Culex mosquitoes and West Nile virus transmission, northeastern United States. Emerg Infect Dis. 2006;12:468-74.

16. Simpson JE, Hurtado PJ, Medlock J, Molaei G, Andreadis TG, Galvani AP, et al. Vector host-feeding preferences drive transmission of multi-host pathogens: West Nile virus as a model system. Proc R Soc Biol Sci Ser B. 2012;279:925-33.

17. Patrican LA, Hackett LE, James E, Briggs JWM, Unnasch TR, Lee J-H Host-feeding patterns of Culex mosquitoes in relation to trap habitat. Emerg Infect Dis. 2007:13:1921-3.

18. Kilpatrick AM, Daszak P, Jones MJ, Marra PP, Kramer LD. Host heterogeneity dominates West Nile virus transmission. Proc R Soc Biol Sci Ser B. 2006;273:2327-33.

19. Takken W, Verhulst NO. Host preferences of blood-feeding mosquitoes. Annu Rev Entomol. 2013;58:433-53.

20. Mansingh A. Physiological classification of dormancies in insects. Can Entomol. 1971:103:983-1009.

21. Sanburg LL, Larsen JR. Effect of photoperiod and temperature on ovarian development in Culex pipiens pipiens. J Insect Physiol. 1973;19:1173-90.

22. Spielman A. Structure and seasonality of nearctic Culex pipiens populations. Ann N Y Acad Sci. 2001:951:220-34.

23. Madder D, Surgeoner G, Helson B. Induction of diapause in Culex pipiens and Culex restuans (Diptera: Culicidae) in southern Ontario. Can Entomol. 1983;115:877-83.

24. Spielman A, Wong J. Environmental control of ovarian diapause in Culex pipiens. Ann Entomol Soc Am. 1973;66:905-7.

25. Eldridge BF: Diapause and related phenomena in Culex mosquitoes: their relation to arbovirus disease ecology. In: Current Topics in Vector Research New York, New York: Springer; 1987:1-28.

26. Bowen MF. Patterns of sugar feeding in diapausing and nondiapausing Culex pipiens (Diptera: Culicidae) females. J Med Entomol. 1992;29:843-9.

27. Mitchell CJ, Briegel H. Inability of diapausing Culex pipiens (Diptera: Culicidae) to use blood for producing lipid reserves for overwinter survival. J Med Entomol. 1989:26:318-26.

28. Farajollahi A, Crans WJ, Bryant P, Wolf B, Burkhalter KL, Godsey MS, et al. Detection of West Nile viral RNA from an overwintering pool of Culex pipens pipiens (Diptera: Culicidae) in New Jersey, 2003. J Med Entomol. 2005;42:490-4.

29. Nasci RS, Savage HM, White DJ, Miller JR, Cropp BC, Godsey MS, et al. West Nile virus in overwintering Culex mosquitoes, New York City, 2000. Emerg Infect Dis. 2001;7:742-4.

30. Anderson JF, Main AJ. Importance of vertical and horizontal transmission of West Nile virus by Culex pipiens in the northeastern United States. J Infect Dis. 2006;194:1577-9.

31. Dohm DJ, Sardelis MR, Turell MJ. Experimental vertical transmission of West Nile virus by Culex pipiens (Diptera: Culicidae). J Med Entomol. 2002:39:640-4.

32. Goddard LB, Roth AE, Reisen WK, Scott TW. Vertical transmission of West Nile virus by three California Culex (Diptera: Culicidae) species. J Med Entomol. 2003;40:743-6.

33. Baqar S, Hayes CG, Murphy JR, Watts DM. Vertical transmission of West Nile virus by Culex and Aedes species mosquitoes. Am J Trop Med Hyg. 1993;48:757-62.

34. Miller BR, Nasci RS, Godsey MS, Savage HM, Lutwama JJ, Lanciotti RS, et al. First field evidence for natural vertical transmission of West Nile virus in Culex univittatus complex mosquitoes from Rift Valley province, Kenya. Am J Trop Med Hyg. 2000;62:240-6.

35. Bailey CL, Eldridge BF, Hayes DE, Watts DM, Tammariello RF, Dalrymple JM. Isolation of St. Louis encephalitis virus from overwintering Culex pipiens mosquitoes. Sci. 1978;199:1346-9.

36. Farajollahi A. Seasonal dynamics of Culex pipiens pipiens L. (Diptera: Culicidae). In: New Jersey and examination of its role as an overwintering reservoir for West Nile virus. New Brunswick, New Jersey: Rutgers University; 2005

37. Andreadis TG, Anderson JF, Vossbrinck CR. Mosquito surveillance for West Nile virus in Connecticut, 2000: isolation from Culex pipiens, CX. restuans, CX. salinarius, and Culiseta melanura. Emerg Infect Dis. 2001;7:670-4.

38. Dohm DJ, O'Guinn ML, Turell MJ. Effect of environmental temperature on the ability of Culex pipiens (Diptera: Culicidae) to transmit West Nile virus. J Med Entomol. 2002;39:221-5.
39. Kilpatrick AM, Meola MA, Moudy RM, Kramer LD. Temperature, viral genetics, and the transmission of West Nile virus by Culex pipiens mosquitoes. PLoS Pathog. 2008;4:e1000092.

40. Reiter P. A portable, battery-powered trap for collecting gravid Culex mosquitoes. Mosq News. 1983;43:496-8.

41. Nelder M, Kesavaraju B, Farajollahi A, Healy S, Unlu I, Crepeau T, et al. Suppressing Aedes albopictus, an emerging vector of dengue and chikungunya viruses, by a novel combination of a monomolecular film and an insect-growth regulator. Am J Trop Med Hyg. 2010;82:831-7.

42. Andreadis TG, Thomas MC, Shepard JJ. Identification Guide to the Mosquitoes of Connecticut. Connecticut Agricultural Experiment Station: New Haven, Connecticut; 2005.

43. Robich RM, Denlinger DL. Diapause in the mosquito Culex pipiens evokes a metabolic switch from blood feeding to sugar gluttony. Proc Natl Acad Sci. 2005;102:15912-7.

44. Hoc TQ, Schaub GA. Improvement of techniques for age grading hematophagous insects: ovarian oil-injection and ovariolar separation techniques. J Med Entomol. 1996;33:286-9.

45. Clements A. The Biology of Mosquitoes. Volume 1. Development, Nutrition and Reproduction, vol. 1. Cambridge, UK: CABI Publishing; 2000.

46. Care IoLARCo, Animals UoL, Resources NloHDoR. Guide for the Care and Use of Laboratory Animals. Washington, DC: National Academy Press; 1996.

47. Lepore TJ, Pollack RJ, Spielman A, Reiter P. A readily constructed lard-can trap for sampling host-seeking mosquitoes. J Am Mosq Control Assoc. 2004;20:321-2.

48. Darbro JM, Harrington LC. Bird-baited traps for surveillance of West Nile mosquito vectors: effect of bird species, trap height, and mosquito escape rates. J Med Entomol. 2006:43:83-92.

49. Simpson JE, Folsom-O'Keefe CM, Childs JE, Simons LE, Andreadis TG, Diuk-Wasser MA. Avian host-selection by Culex pipiens in experimental trials. PLoS One. 2009:4:e7861.

50. Apperson CS, Hassan HK, Harrison BA, Savage HM, Aspen SE, Farajollahi A, et al. Host feeding patterns of established and potential mosquito vectors of West Nile virus in the eastern United States. Vector Borne Zoonotic Dis. 2004;4:71-82.

51. Darbro JM, Harrington LC. Avian defensive behavior and blood-feeding success of the West Nile vector mosquito, Culex pipiens. Behav Ecol. 2007;18:750-7.

52. Thiemann TC, Reisen WK. Evaluating sampling method bias in Culex tarsalis and Culex quinquefasciatus (Diptera: Culicidae) bloodmeal identification studies. J Med Entomol. 2012;49:143-9.

53. Day JF, Edman JD. Mosquito engorgement on normally defensive hosts depends on host activity patterns. J Med Entomol. 1984;21:732-40.

54. Edman JD, Webber LA, Schmid AA. Effect of host defenses on the feeding pattern of Culex nigripalpus when offered a choice of blood sources. J Parasitol. 1974;60:874-83.

55. Anderson RA, Brust RA. Interrupted blood feeding by Culex (Diptera: (ulicidae) in relation to individual host tolerance to mosquito attack. J Med Entomol. 1997;34:95-101.

56. Scott TW, Lorenz LH, Edman JD. Effects of house sparrow age and arbovirus infection on attraction of mosquitoes. J Med Entomol. 1990;27:856-63.

57. Williams CR, Kokkinn MJ, Smith BP. Intraspecific variation in odor-mediated host preference of the mosquito Culex annulirostris. J Chem Ecol. 2003;29:1889-903.

58. Williams CR, Kokkinn MJ. Daily patterns of locomotor and sugar-feeding activity of the mosquito Culex annulirostris from geographically isolated populations. Physiol Entomol. 2005:30:309-16.

59. Ezenwa VO, Godsey MS, King RJ, Guptill SC. Avian diversity and West Nile virus: testing associations between biodiversity and infectious disease risk. Proc R Soc Lond B Biol Sci. 2006;273:109-17.

60. Allan BF, Langerhans RB, Ryberg WA, Landesman WJ, Griffin NW, Katz RS, et al. Ecological correlates of risk and incidence of West Nile virus in the United States. Oecologia. 2009;158:699-708. 